\title{
Active and Passive Factors in Urethral Continence Function
}

\author{
E. J. McGuire \\ Section of Urology, University of Michigan, Ann Arbor, Michigan 48109, USA
}

\begin{abstract}
The function of the urethra can be evaluated with respect to involuntary continence function, volitional contractility - which has no relationship to passive continence - and conduit function. Precise evaluation of continence function usually requires fluoroscopy. The classification of incontinence based on fluoroscopic and manometric findings has a bearing on the selection of an effective operation. Direct urethral pressure measurements are of little value in the diagnosis of urethral dysfunction.
\end{abstract}

Keywords: Continence; Internal sphincter; Pressure; Proximal sphincter; Urethra; Valsalva leak point; Videourodynamics

\section{Introduction}

The urethra has two basic modes of activity. It functions most of the time as an organ of continence, but during micturition it behaves as a compliant conduit. The behavior of the urethra during both modes of activity has been the subject of study generating considerable controversy for many years. Although the observations made clinically and experimentally are similar or identical, the conclusions drawn from those observations vary considerably [1].

There is little question that in females, while the urethra functions as an organ of continence, the highest recorded intraurethral pressures are measured in the mid-urethra $[2,3]$. This is the part of the urethra which traverses the pelvic floor, and which is clearly influ-

Correspondence and offprint requests to: Dr Edward J. McGuire, Professor and Section Head, Section of Urology, University of Michigan, 2916D Taubman Center, Box 0330, Ann Arbor, Michigan 48109, USA. enced by fast twitch skeletal muscle, innervated by the pudendal nerve. This part of the urethra is involved in voluntary efforts to stop voiding on command, and is the active segment of the urethra in reflexly determined detrusor-sphincter dyssynergia seen in females with spinal cord injury or multiple sclerosis. This area is easily visualized radiographically and can be identified endoscopically (Fig. 1).

The urethra proximal to the high pressure zone or area has been variously named the internal sphincter, the smooth or lisso sphincter and the proximal urethral sphincter. For our purposes, it does not matter what this part of the urethra is called. It opens when the bladder contracts, but does not participate in active hyperclosure of the urethral sphincter directed at a contracting bladder. Precisely how this part of the urethra opens when the bladder contracts has also been an area of controversy. However, there is no argument about the basic observation that when the bladder contracts reflexly, this part of the urethra clearly opens [4]. Whether it is pulled open, or relaxes, or even contracts to open, is still argued. For a number of excellent reasons it almost has to relax, but that is another matter. The 'high pressure zone' of the urethra, influenced by the skeletal muscle within the urethral wall and outside it, has a reciprocal relationship with the bladder, as does the 'internal' sphincter superior to it, but the relationship is determined at multiple central neural levels rather than peripherally, as is the case in the relationship between the bladder and the proximal urethra [2]. In the latter case, when the bladder contracts the internal sphincter opens; when the bladder does not, the internal sphincter is closed. We cannot either voluntarily or subconsciously open the internal sphincter: that occurs only when the bladder contracts, and we probably cannot change internal sphincter closing pressure either, although that is more difficult to prove. 

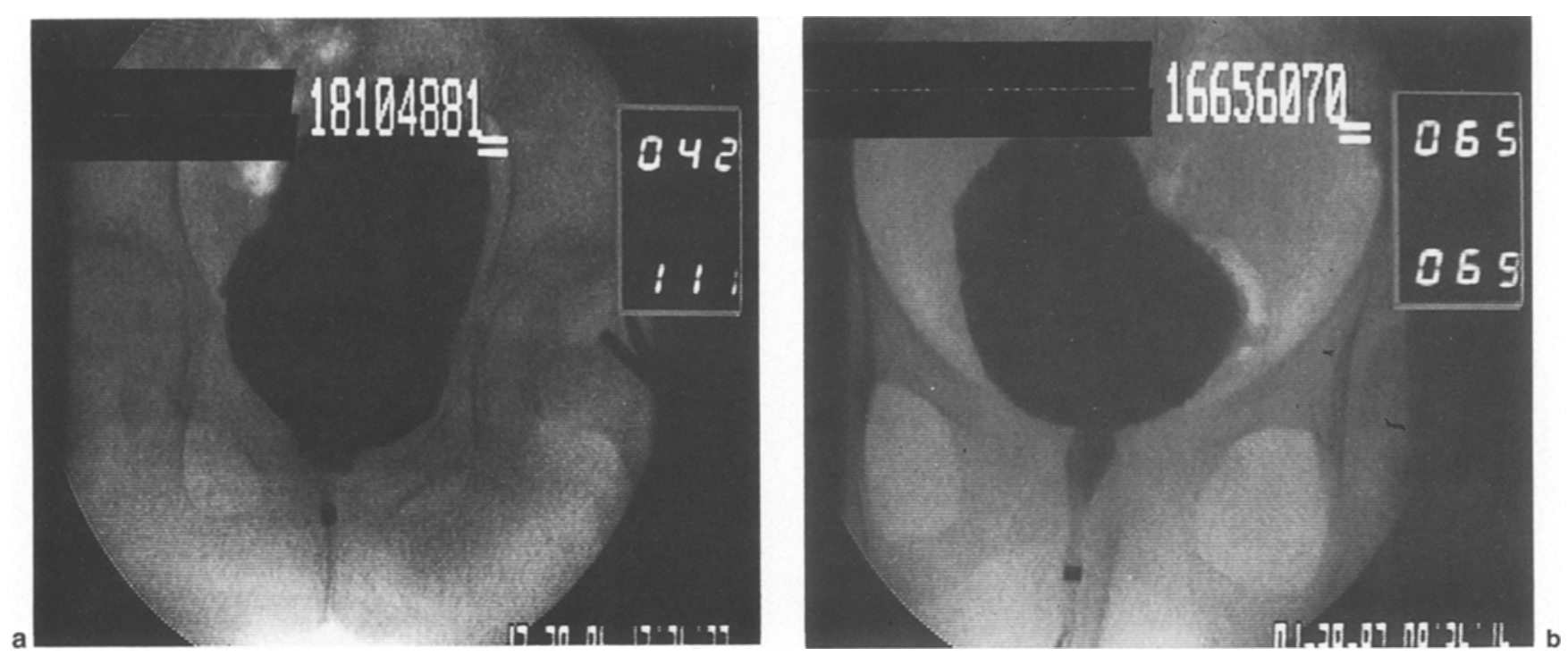

Fig. 1. Location and activity of the 'external sphincter'. a Female patient with a spinal cord injury. Bladder pressure of $42 \mathrm{cmH}_{2} \mathrm{O}$, external sphincter pressure of $111 \mathrm{cmH}_{2} \mathrm{O}$. Note the open 'internal sphincter'; b Female multiple sclerosis patient with detrusor-external sphincter dyssynergia. Note the open vesical outlet, the identical pressures in the bladder and external sphincter. Urethral pressures are measured at the radiographic marker on the urodynamic catheter; c Male spinal cord injury patient with high pressure detrusorsphincter dyssynergia. Note length of urethra showing hyperclosure, the open vesical outlet, and reflux of urine into the vas. Bladder pressure of 136 , external sphincter pressure of $77 \mathrm{cmH}_{2} \mathrm{O}$.

\section{Mechanisms of Continence}

In contrast it is possible, and indeed common, to voluntarily change distal or high pressure zone closing pressure. Normally during the bladder storage phase of activity, pressure in this area does not drop below a certain point, since relaxation of the pudendal nerve innervated components of the urethral sphincter and pelvic floor can permit a detrusor contraction to occur. Indeed, the initial sign of a voluntary bladder contraction is a pronounced fall in mid-urethral sphincter pressure, and conversely attempts to prevent or halt bladder reflex contractility are associated with activity and pressure in this area (Fig. 2).

Periurethral sphincter EMG recordings document electrical activity which correlates with changes in midurethral closing pressure. Normal micturition is associated with electrical silence from the pelvic floor and a persistently relaxed external sphincter area. There is a

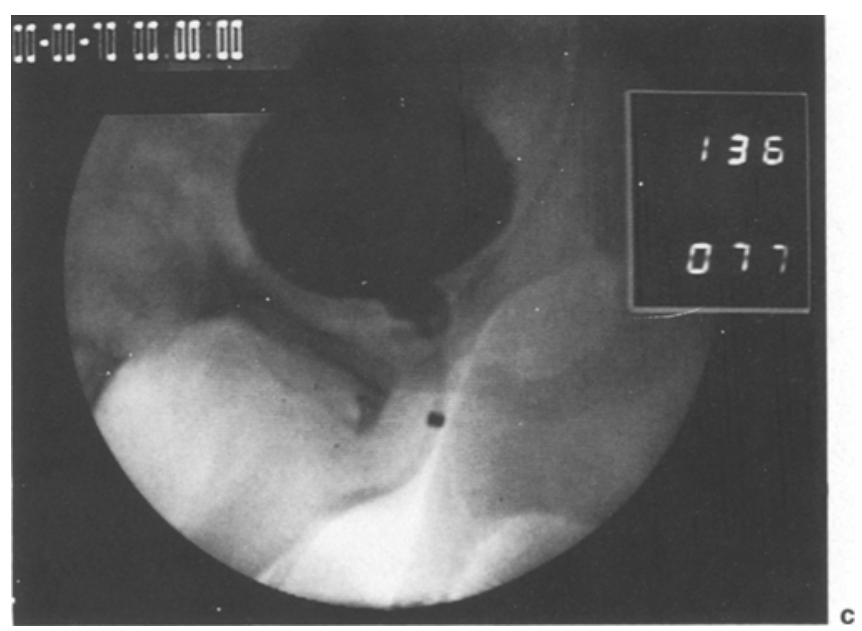

little fall-off in stream pressure from the bladder until just past the mid-urethral high pressure zone. While the relationship between the function of the pelvic floor and distal sphincter, and the bladder, is profoundly disturbed in certain neurological conditions (for example, spinal cord injury), spinal, supraspinal and peripheral lesions do not change the relationship between the 'internal sphincter' and the bladder. If the bladder is areflexic, due to a sacral root lesion, the internal sphincter is closed and stays closed, no matter how full the bladder becomes. If there is reflex function the internal sphincter opens when the bladder contracts, even if the distal sphincter contracts vigorously against the bladder contraction.

While there is no question regarding the innervation of the pelvic floor, there is some question regarding innervation and function of the 'internal sphincter'. This area is said to be closed as a result of a state of relaxation, rather than driven to contractile closure by 


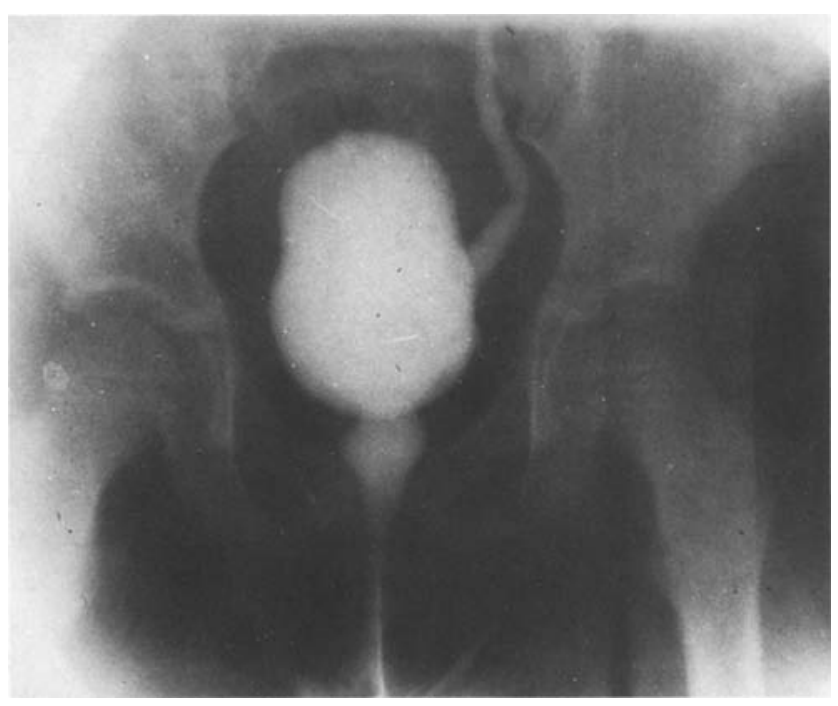

Fig. 2. Voiding cystouretherogram from a 4-year-old girl with dayand night-time incontinence. A sudden detrusor contraction occurred which she tried to stop. Note the hyperclosure at the external sphincter and the open proximal urethra, and the pressure related vesicoureteral reflux.

an active neural process. Alternatively, elastic fibers are said to close this part of the urethra. There is, however, considerable evidence that urethral smooth muscular closure is an active, innervated, muscular process. Females treated with alpha-blocking agents frequently become incontinent; pelvic fracture and certain central or specific peripheral neural injuries result in a widely patulous open internal sphincter mechanism in association with highly variable bladder function, including normal, reflex dyssynergic and areflexic bladders $[6,7,8]$. It is unlikely that peripheral and/ or central neural injury and alpha-blockade would influence elastic fibers or induce a lack of relaxation resulting in a wide open urethra. On a practical clinical level, arguments about the mechanism of function have little relevance. Whether the proximal or internal sphincter functions, and how well it functions, does have very substantial clinical relevance however, since the effective treatment of incontinence depends in part on the accurate assessment of function of this area of the urethra.

Fluoroscopically-guided urodynamic studies are helpful in determining the relationship between urethral closing function and continence, particularly in terms of the function of specific parts of the urethra.

\section{Poor or Absent Proximal Urethral Function}

Myelodysplastic children (at least $80 \%$ of them) show a very ususual type of neurogenic vesical dysfunction, characterized by a decentralized areflexic bladder and an open non-functional internal sphincter mechanism to the level of the mid-urethral high pressure zone (Fig. 3 ). Incontinence related to neurogenic vesical dysfunction is more of a clinical problem in myelodysplasia than in any other patient population with neurogenic bladder dysfunction. Most of these children have a functional mid-urethral high pressure zone, and even if pressures recorded from this area are not normal, there is visible radiographic closure of the area and measurable pressure. The relationship between measured sphincter pressure by the urethral pressure profile technique, and the ability of the sphincter to resist pressure directed against it by intrinsic bladder activity or abdominal pressure, can be determined. In children
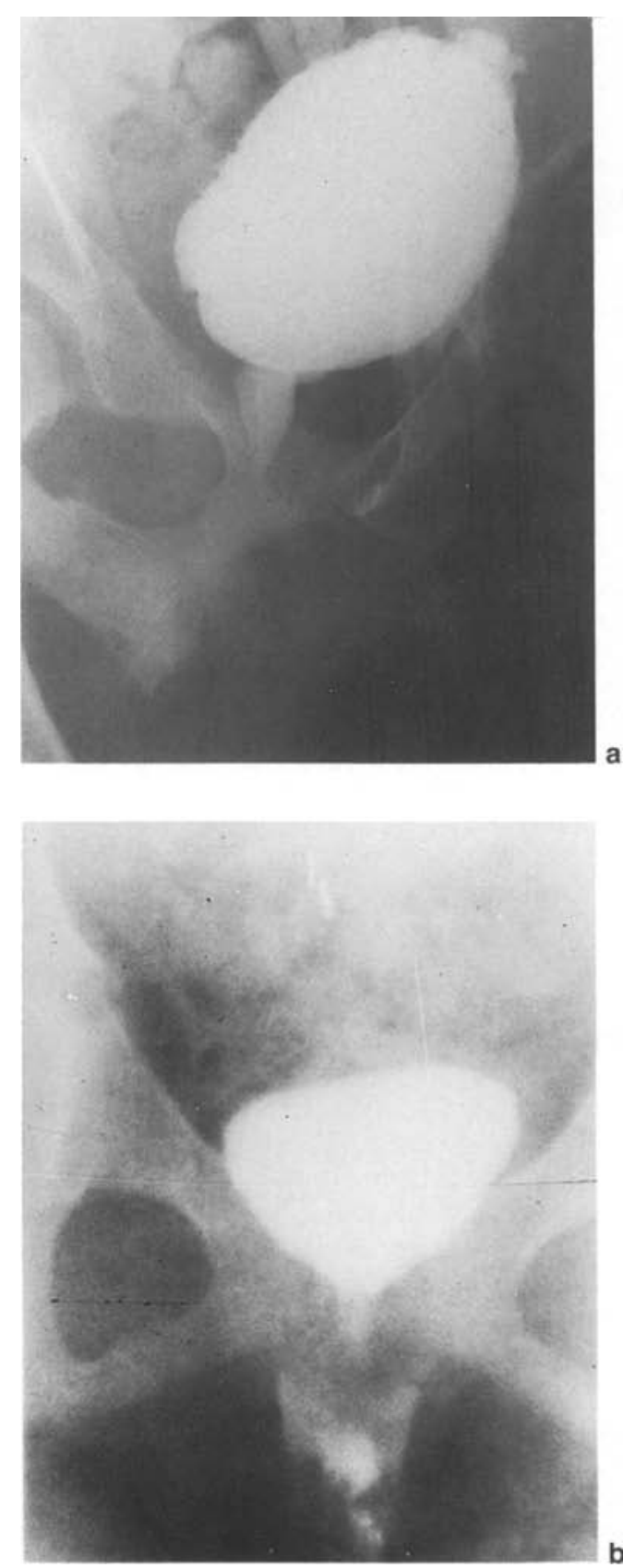

Fig. 3. a Upright cystrogram from a male myelodysplastic child showing a typical open internal sphincter with closure preserved at the 'high pressure zone'; $\mathbf{b}$ Upright cystogram from an 11-year-old myelodysplastic girl. Note the open internal sphincter, and leakages of urine across the 'external sphincter'. 
with myelodysplasia, a supine filling cystometrogram with a non-crying relaxed child, using a $5 \mathrm{Fr}$ feeding tube without an occlusion balloon, will show that bladder filling ultimately results in the generation of an intravesical pressure which overcomes urethral resistance and induces leakage. It can be shown that this pressure is almost identical to peak urethral closing pressure, which in this case corresponds to mid-urethral closing pressure.

If the child is supported in an upright position and performs a progressive Valsalva maneuver, the abdominal pressure required to induce leakage is considerably less than peak urethral closing pressure. Since both pressures are measured in the same place (the bladder), it at first seems unlikely that the findings could be accurate, but the measurement clearly shows that the urethra in this circumstance, that is with an open internal sphincter, resists intrinsic intravesical pressure better than intraabdominal pressure. These findings strongly suggest that we can measure the efficiency of the sphincter visà-vis intraabdominal pressure only indirectly and not by urethral pressure profilometry.

\section{Limitation of Pressure Urodynamics in Relation to Urethral Function}

Consider, for example, patients with post-prostatectomy incontinence. The working rules of urodynamics tell us that if at any time intravesical pressure exceeds urethral peak closing pressure, leakage will occur, and vice versa. Most patients who experience constant dribbling incontinence after radical prostatectomy, do so only in the upright position. They also show an increase in leakage with a change in intraabdominal pressure, i.e. they have genuine stress incontinence. Despite the obvious leakage however, most such patients show reasonable external (membranous) urethral sphincter pressures; indeed, these are higher than upright intraabdominal pressures and by definition, these recorded pressures are incompatible with incontinence. Yet these patients are wet (Fig. 4). The sphincter mechanism after radical prostatectomy resembles that seen in myelodysplasia, and the primary area of dysfunction is proximal to the high pressure zone'.

Similar abnormalities occur in patients with neurogenic vesical dysfunction following abdominoperineal resection for carcinoma of the rectum, or radical hysterectomy for carcinoma of the cervix. Severe incontinence related to poor or absent function of the internal sphincter mechanism with preservation of pudendal innervation and mid-urethral high pressure zone activity occurs in these patients, males or females (Fig. 5).

While it is true that patients who lose the function of both the 'internal' and external sphincter are very wet, and the abdominal pressure required to cause leakage is as low as $5-6 \mathrm{cmsH}_{2} \mathrm{O}$, this situation is unusual and more often we are confronted by patients with isolated
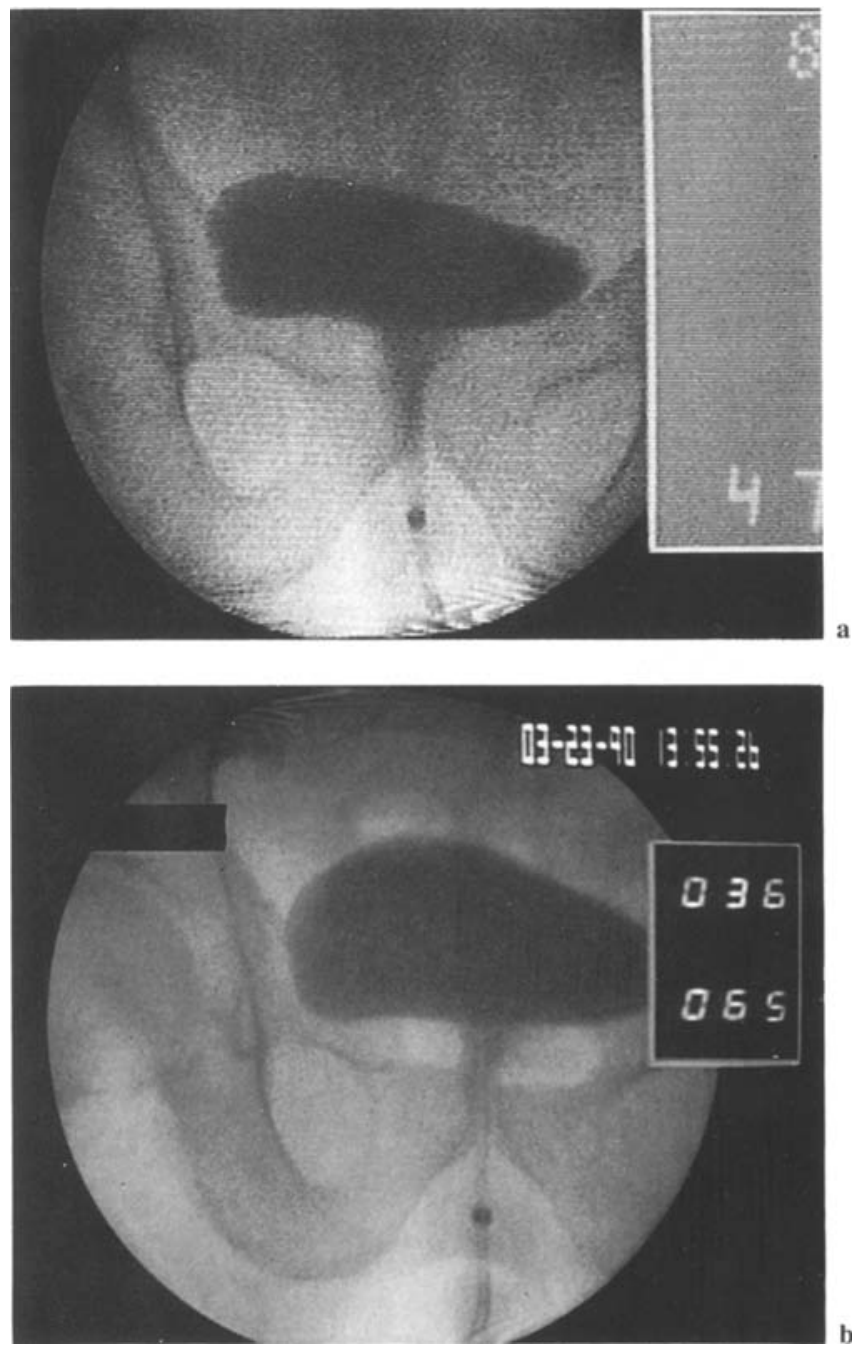

Fig. 4. Resting upright cystogram from a 60-year-old man incontinent after a radical prostatectomy. Note the open internal sphincter, and distal sphincter pressure of $47 \mathrm{cmH}_{2} \mathrm{O} ; \mathrm{b}$ a Valsalva maneuver generates a pressure of 36 in the bladder at which time leakage occurs across the distal sphincter into the bulbous urethra, despite a pressure of 65 in the distal mechanism. An example of leakage at an intraabdominal pressure less than peak intraurethral pressure.

lack of function of the internal sphincter with preservation of reasonable external sphincter function. Since we concentrate on peak profile pressures we miss those patients who show very poor antigravity urethral continence function (Fig. 6). Conversely, deliberate S1 through S5 sacral rhizotomy which was performed in the past in female spinal-cord injured patients to control reflex vesical contractility and lower extremity spasticity, did not induce loss of antigravity continence function. Even though peak urethral closing pressures were much reduced, internal sphincter function was preserved, and these women did not have stress incontinence with transfers or effort.

Thus peak urethral closing pressures do not provide information on internal sphincter function. A more accurate assessment of sphincteric function, particularly antigravity continence function, is obtained by deter- 

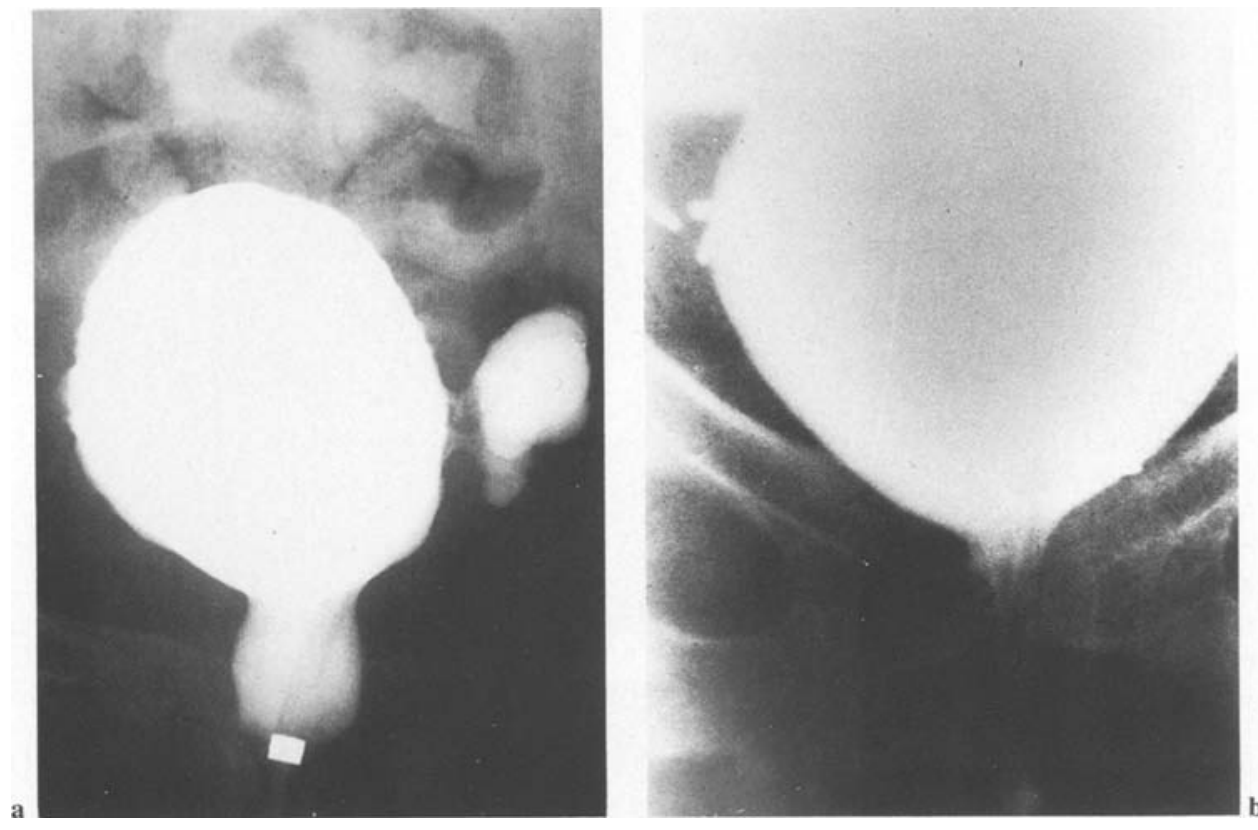

Fig. 5. a Myelodysplastic male child with open vesical outlet and widely dilated proximal urethra with a pressure-related paraureteral diverticulum. The boy is wet with coughing, transfers, and attempts to walk with braces, but the outlet manifests sufficient resistance at the external sphincter to induce the radiographic changes noted; b Sixty-year-old woman incontinent after radical hysterectomy, despite intermittent catherization, note the open vesical outlet.
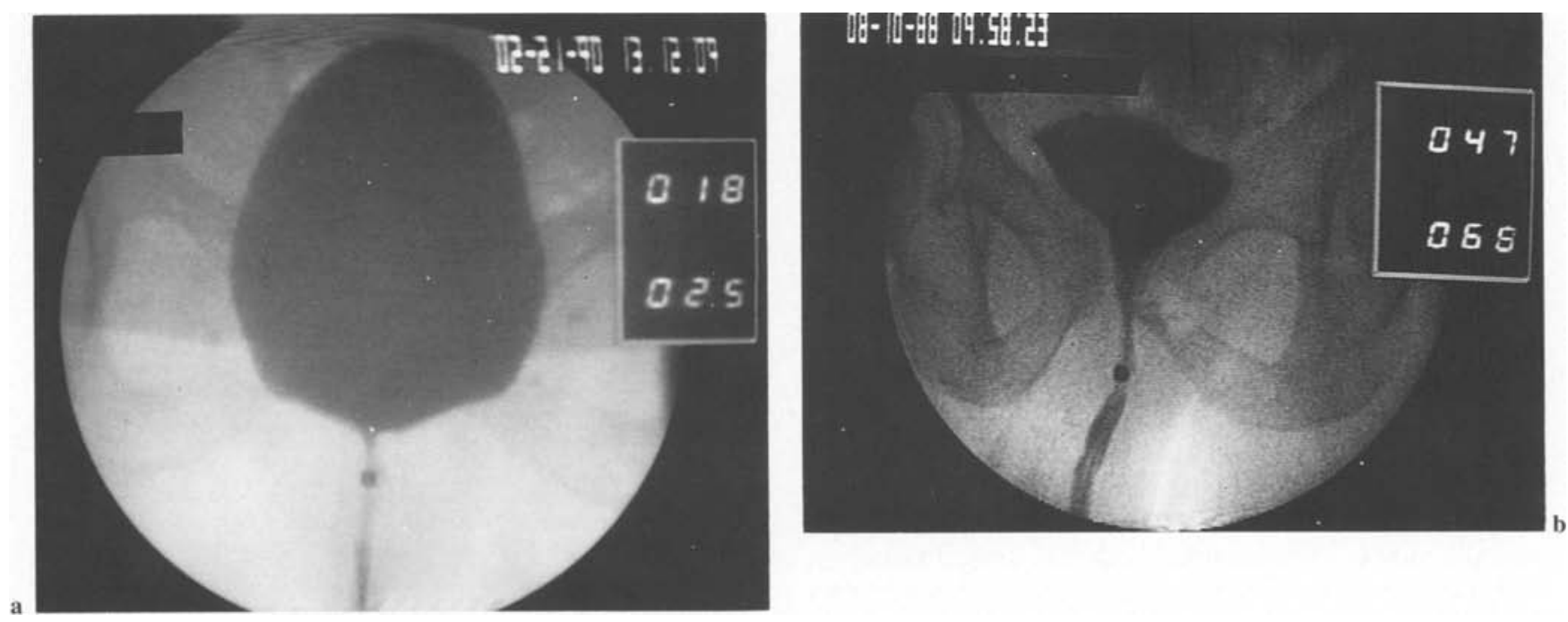

Fig. 6. a Fifty-four-year-old female leaking at a Valsalva generated pressure of $18 \mathrm{cmH}_{2} \mathrm{O}$ across a distal sphincter manifesting a pressure of $25 \mathrm{cmH}_{2} \mathrm{O}$; b Straining film - 65-year-old male with incontinence after a radical prostatectomy. Leakage occurs at a Valsalva-generated pressure of 47 with an external sphincter pressure of $68 \mathrm{cmH}_{2} \mathrm{O}$.

mining the abdominal pressure required to force bladder urine across the sphincter mechanism and cause leakage. The determination of whether leakage occurs can be visual, subjective (the subject reports it) or radiographic. The study must be carried out in the upright position, since the urethra enjoys a mechanical advantage in the supine position.

In a group of 118 patients selected for treatment of incontinence by collagen injection, Valsalva leak point pressures were determined before and after injection. As part of the study, we also used standard, static urethral pressure profiles. Mean Valsalva leak point pressures for women with Type III stress incontinence, males with post-prostatectomy incontinence and myelodysplastic patients are given in Table 1, together with the mean changes in Valsalva leak point pressure after treatment. The peak urethral closing pressure was uninfluenced by collagen injection, even though $60 \%-$ $90 \%$ of the individuals treated were dry following treatment. These observations support the concept of the internal sphincter as an organ of passive continence. Ninety per cent of women with severe Type III incontinence were cured by collagen injection, with a substantial increase in the Valsalva leak point pressure, but no change in peak closing pressure.

Videourodynamic studies of these patients after 
Table 1. Overall outcome of patients treated by collagen injection

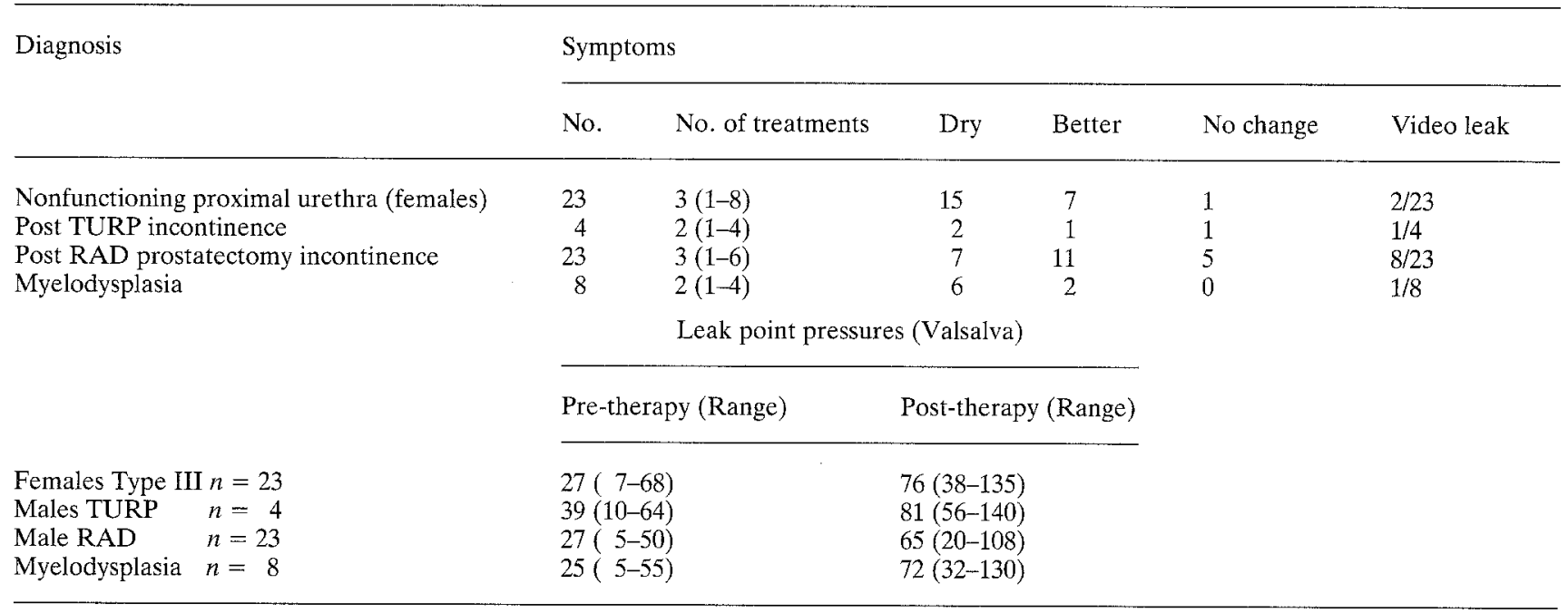

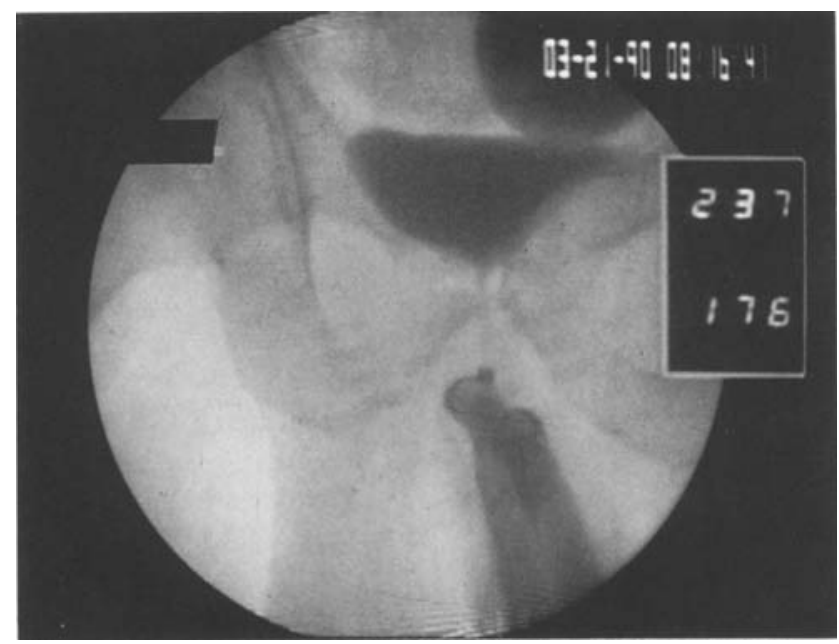

Fig. 7. Valsalva maneuver in 61-year-old patient incontinent after radical prostatectomy, following treatment with injectable collagen. Abdominal pressure is 237, maximum urethral pressure 176, without leakage.

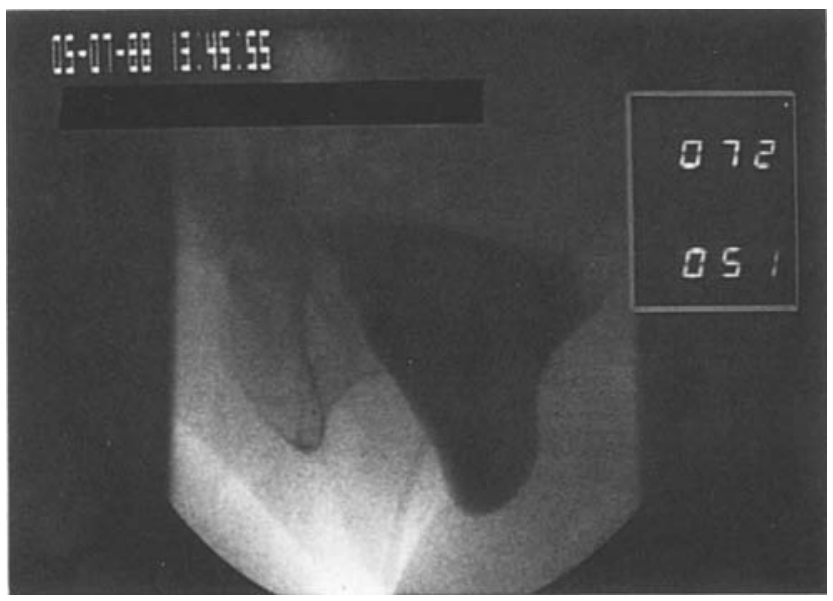

Fig. 8. Straining study from a patient with a moderate cystocele. Valsalva-generated bladder pressure 72 , peak urethral closing pressure is 52 without leakage. The cystocele protects the urethra.
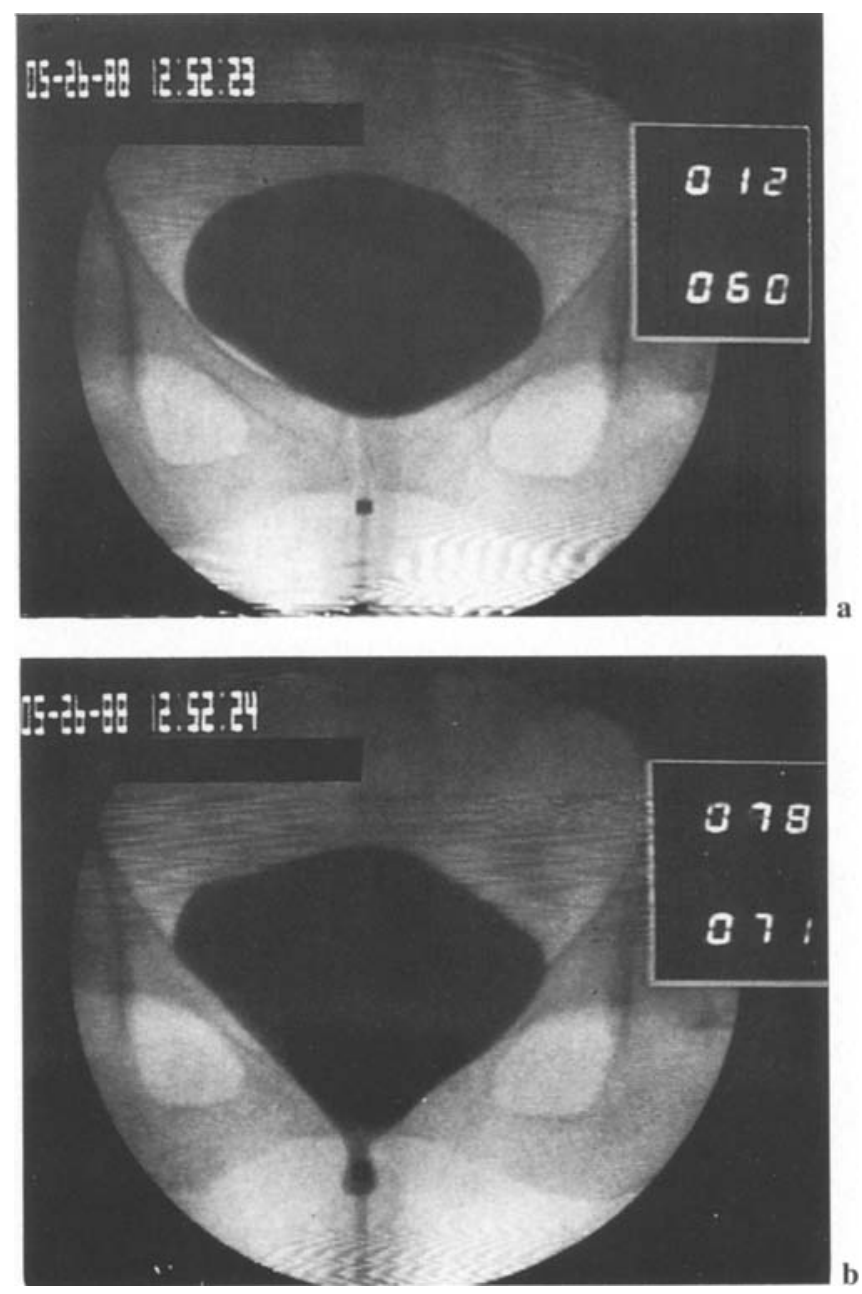

Fig. 9. a Resting study from a 70-year-old woman with severe stress and urge incontinence; $\mathbf{b}$ Straining film at a Valsalva pressure of 78, and a peak urethral pressure of 71 , motion and leakage occur. 
treatment, particularly where maximum urethral closing pressure was previously low, showed many instances where measured valsalva-generated intravesical pressure was higher than mid-urethral pressure, but no leakage occured (Fig. 7). These findings indicate that we cannot rely on intraurethral pressure measurements for the diagnosis of stress urinary incontinence, nor are these useful to determine what happens to the urethra as a result of surgery or treatment. If pressure were the sole determinant of urethral continence function, there would be no advantage to placement of an artificial sphincter in the male bladder neck and we could use the easier approach through the perineum to the bulbous urethra. There is however, a mechanical advantage which bladder neck placement confers so that lesser pressures are required for continence with less chance of erosion. Similar observations pertain to the use of various, now outmoded, prostheses placed in the perineum to compress the bulbous urethra, which had a pronounced tendency to erode due to the applied pressure and yet were not often successful in the treatment of incontinence. Injectable materials (polytetrafluoroethylene and collagen) are distinctly more effective, and yet the pressure these materials exert on the urethral wall and in the urethral lumen are difficult to measure.

A similar urodynamic picture occurs in women with large herniating cystoceles, where intravesical pressure generated by coughing or the valsalva maneuver is higher than peak urethral pressure but no leakage occurs (Fig. 8). On the other hand, in those instances where stress incontinence is associated with normal proximal urethral closing pressures (i.e. pressures specifically measured in the proximal $1 \mathrm{~cm}$ of urethra), and motion of the urethra with changes in intraabdominal pressure, it can be shown that the abdominal pressure required to cause leakage is relatively high (Fig. 9).

\section{Conclusions}

Patients with normal closing pressures do well with standard suspension operations, while those with low proximal pressures and/or low Valsalva leak point pressures do better with sling procedures or collagen injection. While the choice of operative procedures for these conditions is linked to the urodynamic findings, the actual operation is less important than the understanding of how the urethra actually works. The function of the urethra is not related to pressure alone, but where that pressure is exerted.

\section{References}

1. McGuire EJ. Mechanisms of urethral continence and their clinical application. World J Urol 1984; 2:272

2. McGuire EJ. Combined radiographic and manometric assessment of urethral sphincter function. J Urol 1977; 118:632-635

3. McGuire EJ. Evaluation of urinary incontinence. In: Neurourology and urodynamics, principles and practice. Yalla SV, McGuire EJ, Elbadawi A, Blaivas JG, eds. New York, 1988 MacMillan pp 211-220

4. Blaivas JG. The neurophysiology of micturition, a clinical study of 550 patients. J Urol 1982; 127:958-963

5. McGuire EJ. The innervation and function of the lower urinary tract. $J$ Neurosurg 1986; 65:278-285

6. McGuire EJ. Urodynamic evaluation after abdominoperineal resection and lumbar intravertical disc herniation. Urology 1975; 6:63-70

7. McGuire EJ, Wagner SC Jr. The effect of sacral denervation on bladder and urethral function. Surg Gynecol Obstet 1977; $144: 343-346$

8. Woodside JR, McGuire EJ. Urethral hypotonicity after suprasacral spinal cord injury. J Urol 1979; 121:783-785 